\section{Glouds and Shadows.}

In a letter to Nature (April 18) Mr. Chas. Tilden Smith directs attention to a peculiar shadow he noticed in the western sky last Easter Monday after sunset, and which he no doubt correctly attributed to "some unseen object intercepting the sun's rays," and so casting a shadow on the high and still directly illuminated stratus he mentions.

Such shadows are by no means uncommon in lower latitudes, and are certainly caused either by clouds, especially the towering columnar cumuli (so common in the Caribbean Sea) or by mountains. For many years past the writer has been collecting data regarding such shadows and working out the position, size, and shape of the objects causing them. He has succeeded in (a) predicting correctly the form, position, and duration of the shadows caused by mountains for a sunset viewed from a known position (supposing that clouds did not interfere), e.g. from a ship to the east of Cuba, in which case it was possible to assign some of the observed shadows to definite peaks; and $(b)$ he has succeeded in (conversely) deducing from the observed positions and forms of these shadows the general configuration of the mountain ranges which caused them-e.g. off the eastern coast of Brazil.

Such shadows to be seen well require (I) a clear lower atmosphere, and (2) a reflecting layer at a considerable height-e.g. six miles.

The writer hopes to be able before long to publish these and many other observations and deductions, together with the formulæ necessary for the analysis of this part of a sunset.

Upton, Slough, May 3.

\section{THE ROYAL ACADEMY AND NATURE- STUDY.}

THE annual exhibition of pictures at the Royal Academy always affords a good opportunity of examining the works of the several contributors as far as they may be considered representations of natural phenomena.

The following notes have therefore been made regarding such points as clouds, sun, moon, sunset skies, \&c., and these are brought together under their respective heads.

\section{Mists.}

163. The Cradle of the Storm. Frank T. Carter. The mist or low drifting cloud about the mountains is here beautifully portrayed, and the swirl-forms indicate local eddies; the lighting is very true.

190. A Highland Loch. Peter Graham, R.A. Beautifully graded mists on the mountain sides, and the effect of the rift, which is an important feature in the picture, is well indicated.

\section{Clouds (Nimbi or Rain Clouds).}

22. The Midlands. C. E. Johnson. Cloud forms ind colour very good. Excellent representation of a rain squall on the right.

I69. The Hunters, C. Napier Henry, R.A. Form and colour and general arrangement of the clouds quite natural.

I7o. Dryslwyn. T. Hodgson Liddell. The cloud forms here are accurately shown, but the falling rain is not well represented, being not sufficiently transparent for such a close squall.

184. A Passage Perilous Maketh a Port Pleasant. W. L. Wyllie, R.A. The cloud forms and colour here NO. 22 I9, VOL. 89] are very natural, and the reflection on the water true.

189. The Passing Snowstorm. Ernest Procter. The clouds here are too dark and coarse. (When looked at from some distance the effect is improved.)

193. Bredon on the Avon. Alfred Parsons, R.A. Both form and colour of the clouds beautifully represented. A fine cloud study and one to be copied.

221. Rain Clouds: Bosham. Moffat Lindner. The large nimbus is far too solid-looking and lacking in detail. Such a cloud in nature is full of detail, both in structure and light gradations. As here depicted it looks like a lump of dough.

285. The Approaching Shower. Beatrice Bland. Both the clouds and falling rain are well represented. The shower, however, is not approaching but travelling nearly from left to right, as indicated by the slant of the falling rain.

II7. The Approaching Gale. Julius Olsson. The clouds and waves are both good in form, but why the violet colour in both?

359. Stormy Evening on the Cornish Coast. Julius Olsson. This picture, like $\operatorname{I} 7 \mathrm{7}$ above, is too violet all over.

36o. Evening on the Nebelhorn, Bavaria. Edward T. Compton. The contrast between the fair weather on the right of the picture, the approaching rain clouds on the left, and the brightly illuminated snowfields in the foreground is well thought out and rendered very true.

\section{Clouds (Cumuli, Fine Weather Clouds).}

20. Woodland and Hill. Sir E. A. Waterlow, R.A. Very fine representation of clouds with excellent detail and gradation. Perhaps some of the upper portions of them are not white enough.

40. The Incoming Tide: Porth, New Quay. B. W. Leader, R.A. Good cloudscape, but must not be looked at too closely to obtain desired effect.

81. Submarines and Torpedo Craft: Old Portsmouth. W. L. Wyllie, R.A. Most excellent clouds, showing the result evidently of much observation. Indications of ascending air and upper horizontal air currents very natural. Reflection on water well graded.

II5. The Hills of Appin. J. Campbell Mitchell. Forms of clouds most unnatural. Too much drawn out vertically, and little detail shown.

162. Marazion Marsh, Cornwall. J. Noble Barlow. Clouds badly formed, and, like those in II5, too vertical.

323. The Home of Labour. E. Blair Leighton. No idea of cloud form, and lighting all wrong. Clouds are drawn out like 115 and 162 .

393. "The Toiling Year's Last Breath." Frank Walton. The clouds are good, both in form, detail, colour, and gradation. Their lower flat surfaces should be horizontal and not all inclined similarly.

46r. The Walls of England. R. Grelo Goodman. Absolutely impossible skyscape.

582. Spring Sunshine. Alfred Parsons, R.A. The cumuli clouds and sky are here very naturally depicted, and the artist has blended the sky with the landscape most successfully. The tints of the blossoms on the trees are true and admirably represented.

75.5. A Fine Morning on the Sussex Coast. B. W. Leader, R.A. A well-painted and natural skyscape with the same proviso as 40 .

129. The Mass at Dordrecht. Moffat Lindner. Well-shaped cumuli and good reflections of clouds in water.

I98. Skirt of the Dunes at Condette, Pas-de-Calais. H. W. B. Davis, R.A. Gradation of blue sky from horizon upwards is possibly changed too suddenly. 


\section{Clouds (Cirrus, High Clouds).}

390. A Gentle Breeze. Hon. Duff Tollemache. Form and colour of the cirrus cloud very natural.

505. Fifteen-metre Vachts Rounding the East Lepe Buoy: Cowes Regatta. Alice Fanner. The cirrus cloud in this seascape is very good. The small cumuli and wisps of cirrus very natural.

689. Six-metre Yachts Racing at the International Regatta, Solent, I9II. Alice Fanner. The cirrus clouds are well represented.

\section{Sunsets, Sunrises (Sky).}

13. Scur-na-Gillian, Sligachan. Finlay Mackinnon. A beautiful picture with a bold effect of sunset. Is not the near side of the right-hand peak too much illuminated?

55. Evening on the Sands of Towyn. B. W. Leader, R.A. A fine sunset sky; shape and colour of clouds very true. Reflection in water and breaking wave very effective. A fine picture.

147. "The Day was Sloping towards his Western Bower." Joseph Farquharson, A. Have we not here a too great diversity of colours? Should not the yellow tinge be more universal and be more represented on the hill on the left (which seems too pink) and also on the under portions of the clouds?

205. Evening's Last Gleam. B. W. Leader, R.A. $A$ fine study and lighting excellent. The sunlight on the upper portion of the clouds very effective.

429. The Matterhorn, from the Triftkummen: Sunrise. Edward T. Compton. The colours here are very true in tone, and the wisps of mists on the mountains appear already to be in the process of being dissipated.

465. The Prize. Donald Maxwell. A bold picture. Very striking sunset effect, both in the sky and by refiection. Excellent colouring.

669. A Peaceful Valley. Hon. Walter James. This sunset scene is accurately painted, and the cloud forms, colouring, and general gradation of the tones very true. The atmospheric absorption in the distant landscape naturally indicated.

790. Into the West. Robert W. Allen. The sequence of the colouring at the different altitudes very natural. The type of cloud represented is true, but there is not sufficient of the sunset colours reflected in the water.

\section{Sun's Disc.}

29. The Wane of an Autumn Day. J. Coutts Michie. The disc of the sun is very much too large, and, judging by the angles subtended by the objects in the foreground, it is more than twice the size it should be.

\section{Moon.}

353. Moonrise: the Dunes, Pas-de-Calais, France. $H$. Hughes-Stanton. The full moon much too large, judging by the trees in the foreground.

369. Moonlight on the Cornish Riviera. R. Borlase Smart. Moon too large for similar reasons; also sky around the moon too blue.

782. Moonrise over the Marsh. Stuart Lloyd. The moon here is more natural, but still a little too big judging by the trees in the foreground.

122. Evening. William Brock. In this picture only a small portion of the upper part of the moon is seen above the horizon. By its horizontal extent and curvature it is very much too large, and calculations suggest that if the whole disc were visible it would be three or four times too large.

123. Truilight. Fred Hall. The size and colour of the moon are good. The woman and cattle in foreground are perhaps too much illuminated.

I51. An Autumn Evening in the Alps.

NO. 22 I9, VOL. 89]
Stokes, A. The sun is here supposed to be below the horizon on the right, consequently the visible illuminated portion of the moon ought to be leaning slightly over to the right also, and not as shown. The clouds are also too bright relative to the moon.

\section{Rainbow.}

468. The Home Port. W. Ayerst Ingram. This would be a fine picture if the rainbow were omitted. The sun is setting on the right of the picture more than $90^{\circ}$ away from the observer. This can be gathered from the position and sunlight on the ship in the centre of the picture and other illuminated objects. As one of the fundamental conditions for seeing a rainbow is that the sun should be at the back of the observer, it is not possible for a rainbow to be included in the picture under the existing sunset position.

\section{ReFLECTIONS.}

i67. A Little Mishap. Sir E. J. Poynter, Bart., P.R.A. An excellent study of reflections.

William J. S. Lockyer.

\section{INTERNATIONAL ASSOCIATION OF CHEMICAL SOCIETIES.}

THE International Association of Chemical Societies held its first formal meeting in Paris in April, rgrr, when the delegates nominated by the French, German, and English Chemical Societies met and ratified the statutes of the association, the council of which as at first constituted consisted of Profs. Béhal, Hanriot, and Haller representing the Société Chimique de France, Profs. Jacobson, Ostwald, and Wichelhaus representing the Deutsche chemische Gesellschaft, and Profs. Frankland, Meldola, and Sir Wm. Ramsay representing our Chemical Society. The second conference was held in Berlin last month, under the presidency of Prof. Ostwald and the vice-presidency of Prof. Wichelhaus, when the council was further enlarged by the addition of Profs. Carrara, Oglialoro, and Paternò representing the Italian Chemical Society, Profs. Kurnakow, Tschugaeff, and Walden representing the Russian Chemical Society, Dr. Day and Profs. Noyes and Richards representing the American Chemical Society, and Profs. Fichter, Guye, and Werner representing the Swiss Chemical Society. Certain other societies representative of Holland, Denmark, Austria, and Norway were also affiliated, but were not directly represented on the council. Prof. Meldola, having been unable to attend the meeting, withdrew from the representation of the Chemical Society, and was replaced by Prof. Crossley.

The first work of the Association is the consideration of the nomenclature of inorganic and organic chemistry and the unification of the notation of physical constants. In connection with the latter part of the programme, the committee has been strengthened by the addition of M. Marie, of the French Society of Physical Chemistry. The English committees appointed to report upon these preliminary branches of work are, for inorganic nomenclature, Sir Wm. Ramsay, Dr. J. C. Cain, and Dr. Harden; for organic nomenclature, Profs. Kipping and Wynne and Dr. 